\title{
“QUEMAR HUESOS ES COSA DEL DEMONIO": LA PROHIBICIÓN DE QUEMAR LOS RESTOS ÓSEOS DE LAS PRESAS ENTRE LOS LACANDONES DEL NORTE
}

\author{
“Burning Bones Is a Thing of the Devil": The Prohibition \\ of Burning the Skeletal Remains of Preys Among \\ THE NORTHERN LACANDONS
}

\author{
Alice Balsanelli* \\ doi: https://doi.org/10.31644/ED.V8.N2.2021.A02
}

\begin{abstract}
Resumen: En la mayoría de las sociedades cazadoras indígenas está vigente el tabú que prohíbe quemar los huesos de las presas. El mismo se observó entre los lacandones de Chiapas, en el ámbito de mis estudios sobre la cacería lacandona entendida como un complejo ritual. Se buscará explicar las razones de esta prohibición: se introducirán brevemente las nociones escatológicas mayas y la significación simbólica atribuida a los huesos. Posteriormente, se evidenciará el paralelismo entre el manejo de los restos humanos y de las presas, demostrando que los huesos se consideran elementos activos, portadores de esencias anímicas y que, por lo tanto, no pueden ser manejados como desechos. Se acudirá a trabajos etnográficos realizados en otras sociedades cazadoras y a datos de campo inéditos para demostrar la importancia del tabú que nos concierne en el presente escrito.
\end{abstract}

Palabras clave: lacandones, cacería, huesos, cremación, inframundo.

Abstract: In many indigenous hunting societies, we observe the presence of the taboo that prohibits burning the bones of the prey. The same was noticed among the Lacandons of Chiapas, in the course of my studies on Lacandon hunting as a ritual complex. We will seek to explain the reasons for this prohibition: we will introduce the Mayan eschatological notions and the symbolic significance attributed to the bones. Later, we will seek to establish a comparison between the handling of human and animal remains, demonstrating that bones are considered as active elements, carriers of animic essences and that, therefore, cannot be handled as waste. We will resort to ethnographic

\footnotetext{
* Dra. en Antropología, Programa de Becas Posdoctorales, Centro de Estudios Mayas, Instituto de Investigaciones Filológicas de la Universidad Nacional Autónoma de México, México. ORCiD: https://orcid.org/0000-0002_ 4785-5554. Correo-e: alice.balsanelli@yahoo.com.
}

Fecha de recepción: 27/10/2020. Fecha de aceptación: 10/03/2021. Fecha de publicación: 30/07/2021.

\section{(cc) BY-NC-ND}

EntreDiversidades. Revista de Ciencias Sociales y Humanidades, Vol. 8, Núm. 2 (17), julio-diciembre 2021. Páginas: 30-55 ISSN-e: 2007-7610. https://doi.org/10.31644/ED.V8.N2.2021.A02 
works carried out in other hunting societies, along with unpublished field data, to demonstrate the importance of the taboo concerning us in this paper.

Keywords: Lacandons, hunt, bones, cremation, underworld.

\section{Introducción: antecedentes, métodos de investigación y justificación}

En el presente escrito, se plantea una discusión derivada de mi investigación posdoctoral, cuyo tema central es la cacería lacandona, estudiada desde el punto de vista ritual. La cultura de los lacandones o Hach Winik (Hombres Verdaderos, en lengua maya) ha captado el interés de numerosos académicos desde la primera década de 1900, quienes nos heredaron un rico corpus de obras imprescindibles para su comprensión. Entre ellas, es preciso mencionar el trabajo pionero de Tozzer (1907), las investigaciones de los Baer (1950), de los Soustelle (1966) y las numerosas contribuciones de Bruce, quizá el más profundo conocedor de la cultura de los Hombres Verdaderos del siglo pasado (1971, 1974), entre otras. Por lo general, los autores mencionados se enfocaron en la cosmogonía, la religión y el sistema ritual, hoy temas lamentablemente caídos en desuso (Trench, 2005). Algunos estudiosos contemporáneos han evidenciado que el empleo de estas fuentes bibliográficas como referencias primarias contribuyó a la reiteración de una imagen estática y anacrónica del grupo lacandón, ya que en ellas se enfatizan constantemente las conexiones entre los Hombres Verdaderos y los antiguos mayas (Palka, 2005: 23-29; 45). En palabras de Tim Trench: "Se ha destacado su pasado maya, pero tendiendo a tratar a los lacandones como fósiles 'vivos' que ofrecen pistas a un entendimiento de la época clásica” (2005: 52).

Por esta razón, para el desarrollo del presente escrito y del proyecto del cual forma parte, las fuentes históricas se tomaron en cuenta de manera cautelosa y con dos finalidades: en primer lugar, para investigar sobre las antiguas prácticas cinegéticas lacandonas — hoy casi olvidadas — y, posteriormente, para interpretar los datos recabados en campo, efectuando así una comparación entre la situación etnográfica pasada y la presente. Así, se consideraron también obras de autores contemporáneos, entre las que destacan los trabajos de Didier Boremanse, quien analiza diferentes aspectos de la cultura lacandona ofreciendo un conjunto de contribuciones que versan sobre varios temas $(1998,2006)$. Su trabajo más reciente (2020) consiste en el estudio de los ritos lacandones y de las concepciones inherentes al espacio sagrado, enriquecido por datos de campo en lengua nativa. También, se revisaron las obras del arqueólogo Joel Palka, quien realizó estudios interesantes sobre la historia de los Hach Winik y de los grupos que los antecedieron en la Selva Lacandona, dando también cuenta de los cambios culturales y de la situación etnográfica actual (2005, 2014, 2018). Se señala de igual forma la nueva contribución de la lingüista canadiense Suzanne Cook, quien brinda la colección más reciente de cantos, conjuros y leyendas en idioma original, algunos inéditos, fruto de un largo trabajo de campo y de traducción (2019).

EntreDiversidades. Revista de Ciencias Sociales y Humanidades, Vol. 8, Núm. 2 (17), julio-diciembre 2021. Páginas: 30-55 ISSN-e: 2007-7610. https://doi.org/10.31644/ED.V8.N2.2021.A02 
Junto con la revisión bibliográfica, se llevó a cabo un trabajo de campo continuativo y constante, ${ }^{1}$ aunado al aprendizaje del idioma indígena, que permitió acceder a un mayor número de informantes y buscar nuevos ejes de interés. La presente investigación surgió de una inquietud que se originó en el transcurso de diez años en campo, al observar que la cacería era un tema constante en los discursos de los informantes, pero que no había sido abordado de manera exclusiva en ninguna etnografía. Me planteé, entonces, afrontar la caza como un sistema ritual, siguiendo los estudios de otros autores que se han dedicado al análisis del mismo tema, tanto en el ámbito mesoamericano (Dehouve, 2008; Olivier, 2015; Braakhuis, 2001, entre otros) como en otros contextos geográficos (Hamayon, 2009; Lot-Falck, 2018 [1953]; Nadasdy, 2007; Willerslev, 2004; Århem, 1996; Cayón, 2012, entre otros).

Cabe destacar que la cacería ha sido un tema poco abordado en Mesoamérica, ya que esta zona fue siempre considerada como uno de los focos de la invención de la agricultura y no como región de caza (Dehouve, 2008: 3), por lo que tampoco entre los estudios mayas se han llevado a cabo numerosas investigaciones inherentes al tema (Dillon, 1988). De igual manera, Olivier menciona la necesidad de "llenar un vacío etnográfico" (2015: 142), al proponerse investigar la caza y la simbología del venado en las fuentes históricas y etnográficas. No obstante, cabe señalar que la cacería nativa ha despertado un nuevo interés entre los académicos, como lo demuestran los estudios que ya se mencionaron y otros trabajos recientes (Anderson y Tzuc, 2005; Anderson, 2009; Tuz Chi, 2009; Gabriel, 2010; Meehan, 2013), junto con algunos ensayos publicados en revistas de etnobiología que dan cuenta de los ritos que anteceden y suceden a la caza —la petición ante los dueños, las ofrendas rituales y la bendición de las armas- y, asimismo, aclaran las relaciones entre los cazadores y las instancias sobrenaturales que protegen la fauna (Ramírez y Naranjo, 2007; Santos-Fita, et al., 2013, Santos-Fita, et al., 2015; Herrera-Flores, et al., 2018). También, destacan los estudios arqueológicos que apuntan hacia el análisis de los depósitos rituales encontrados en cuevas, especialmente en la región atiteca, centrados en la significación simbólica de la devolución de los restos de las presas a las entidades protectoras de la fauna (Brown, 2005, 2009; Brown y Emery, 2008).

Por lo general, los estudiosos sobre la cacería destacan la importancia social y ritual que esta actividad cobra en los contextos indígenas (Dehouve, 2008), en oposición a su papel en la cultura occidental, donde se considera como un medio de subsistencia o bien como una actividad lúdica. De esta manera, Dehouve, en el ámbito de sus investigaciones en Guerrero, define un "modelo cinegético mesoamericano", que presenta tres etapas principales: la preparación ritual de la presa y continencia, el recibimiento ceremonial de las presas y la separación de la carne y de los huesos, los cuales, estos últimos, deben devolverse a los dueños de los animales (2008: 4).

De acuerdo con los autores que trabajan el tema de la cacería en contextos indígenas, la caza representa un momento fundamental de interacción entre los humanos y las instancias sobrenaturales que protegen la fauna. Así, la depredación encuentra su justificación en el ámbito ritual, en el marco de un contrato establecido entre los cazadores y los dueños —o dioses— que

\footnotetext{
${ }^{1} \mathrm{Mi}$ investigación se sitúa entre los lacandones del norte, asentados en las comunidades de Nahá y Metzabok, Municipio de Ocosingo, Chiapas. La misma empezó en el año 2011, en el ámbito de mis estudios de Maestría y Doctorado en la Escuela Nacional de Antropología e Historia de México, y continúa hasta la fecha.
}

EntreDiversidades. Revista de Ciencias Sociales y Humanidades, Vol. 8, Núm. 2 (17), julio-diciembre 2021. Páginas: 30-55 ISSN-e: 2007-7610. https://doi.org/10.31644/ED.V8.N2.2021.A02 
conlleva un conjunto de obligaciones y el respeto de determinados tabúes, que son culturalmente variables, pero que apuntan hacia un mismo fin: 1) permitir la toma de recursos naturales (en este caso, las presas), 2) mantener una buena relación entre humanos y no-humanos, que normalmente estriba en la alianza, y 3) legitimar la violencia implícita en la caza, que conlleva el sacrificio de seres que son considerados entes dotados de alma, y que son pertenencia de los dueños o de los dioses que los tutelan. ${ }^{2}$

Con respecto a los lacandones, ya se aclaró que en este grupo la cacería no ha sido abordada como un tema per se, sin embargo, sí se ha tratado en descripciones etnográficas, donde es mencionada como un importante medio de subsistencia que complementaba la agricultura en el aprovisionamiento de alimento (Tozzer, 1907: 71; Soustelle, 1966: 10; Baer y Merrifield, 1972: 236). Así, en algunas etnografías se encuentra información relativa a las especies cazadas, a las técnicas para capturar las presas, así como a las trampas y armas empleadas (Soustelle, 1966; Baer y Merrifield, 1972; Marion, 1991). Aunado a lo anterior, se señalan algunos cuentos lacandones que narran las vivencias de cazadores desmedidos castigados por los dueños de la fauna, o por los mismos animales (Marion, 1991; Boremanse, 2006). Estos dan cuenta del valor atribuido al respeto de las normas éticas en la cacería, y también recalcan la importancia de la relación que los cazadores mantienen con los seres que protegen a la fauna. No obstante, no se encuentra información exhaustiva relativa a las significaciones rituales de la cacería: los conjuros que preceden las batidas de caza, las reglas que los cazadores respetan antes de matar a una presa —abstinencia sexual, algunos tabús alimenticios_ o los ritos de devolución de la carne a los dioses; y, finalmente, no se dispone de datos inherentes al manejo de los restos de las presas.

Por ello, para estudiar las concepciones cinegéticas lacandonas, se otorgó gran importancia a los datos de campo y a los testimonios de los informantes. De hecho, los Hach Winik del norte se encuentran hoy asentados en la Reserva Natural Nahá-Metzabok (estado de Chiapas), donde la cacería es prohibida y solo los miembros más ancianos del grupo recuerdan las batidas de caza y pueden dar cuenta de los ritos que las precedían y seguían. A pesar de las restricciones, se considera aún lícito cazar los animales que entran a las milpas y que amenazan los cultivos: por lo general, se trata de pequeños mamíferos y roedores. Por el contrario, se abandonó la caza de grandes mamíferos, como jaguares, monos, venados o jabalís, y de otras especies protegidas por la Reserva, como el loro cabeza azul, el tucán y otras aves silvestres en peligro de extinción. Por consiguiente, cayeron en desuso las batidas de caza, mientras que sigue vigente la cacería en las

\footnotetext{
${ }^{2}$ Jensen (1986 [1966]) aclara que en la mayoría de los grupos cazadores contemporáneos no encontramos “dioses de la fauna" propiamente dichos, sino un conjunto de seres sobrenaturales que protegen a los animales silvestres y regulan la cacería: espíritus, señores, dueños (véase también Brelich, 2002 [1970]: 44). De acuerdo con la tesis del autor es posible que cuando las sociedades indígenas se sustentaban principalmente de la caza y la recolección, las entidades que protegían la fauna gozaban de mayor importancia, considerándose así como dioses. Tras el abandono del nomadismo y la consolidación de la agricultura como el medio primario de sustento, es de asumirse que los dioses de los animales perdieran importancia, convirtiéndose así en figuras de menor rango. De hecho, en algunos grupos mayas aparecen solo "dueños de la fauna" y "patronos de cacería", como es el caso de los mayas yucatecos y peninsulares (Redfield y Villa, 1962 [1934]; Anderson y Tzuc, 2005). En otros contextos, la figura de un "dios de los animales" se fusionó con otras instancias sagradas: en los grupos mayas de Guatemala y México, con frecuencia los dioses de los animales aparecen a la vez como deidades de los cerros, de las cuevas y de los volcanes, desempeñando así diversas funciones (Thompson, 1930; Guiteras, 1965; Garza, 1984; Tedlock, 1992; Köhler, 2007).
}

EntreDiversidades. Revista de Ciencias Sociales y Humanidades, Vol. 8, Núm. 2 (17), julio-diciembre 2021. Páginas: 30-55 ISSN-e: 2007-7610. https://doi.org/10.31644/ED.V8.N2.2021.A02 
milpas, ${ }^{3}$ lo que le otorga a las actividades cinegéticas un carácter fortuito y contingente y, por consiguiente, no sancionable por parte de las autoridades que protegen la Reserva. No obstante, en el pasado los hombres solían organizarse antes de ir de cacería, una actividad que se llevaba a cabo en la selva y que requería horas para la búsqueda de las presas y su obtención (Baer y Merrifield, 1972: 236; datos de campo).

A pesar de que la caza se practique de manera esporádica y controlada, en campo se observó que aún siguen vigentes las reglas culturales que moderaban dicha actividad en el pasado, y que forman parte del complejo ritual cinegético. El presente ensayo examinará la prohibición de quemar los huesos de las presas. Para ahondar en las significaciones de este importante tabú, se empezará con una revisión del material histórico que permite elucidar la significación simbólica del elemento "hueso". Se introducirán brevemente las nociones escatológicas mayas, considerando tanto el tratamiento ritual de los despojos humanos como el de las presas, con la finalidad de establecer un paralelismo. También, serán introducidas las nociones mayas inherentes al elemento ígneo y a la cremación. Los datos presentados en los primeros dos apartados permitirán entender por qué los huesos de las presas no pueden ser quemados, debiendo ser conservados o bien devueltos a los "dueños de la fauna".

\section{Los huesos: el soporte del alma}

En razón de su carácter durable, en las concepciones indígenas los huesos adquieren una profunda significación simbólica, que se refleja en un amplio abanico de prácticas culturales y creencias que serán discutidas en el presente apartado. Sin pretender agotar el tema, sobre el cual existe abundante bibliografía, a continuación se señalan algunos puntos fundamentales que permitirán entender los ritos de conservación de los restos de las presas y explicar el tabú que prescribe la prohibición de arrojarlos al fuego.

Los estudios inherentes a las concepciones escatológicas mesoamericanas apuntan a que los huesos se consideraban portadores de determinadas esencias anímicas, que permanecían en los restos de los difuntos. Estos eran conservados y considerados como poderosas reliquias, en cuanto retenían parte de las instancias espirituales de sus dueños (López, 1980: 177).

Es sabido que, en concepto de los mayas, el cuerpo está animado por una cantidad variable de "almas", dotadas de características heterogéneas: algunas corresponden a órganos materiales, otras son impalpables; unas se albergan en el interior del organismo, mientras que otras se hallan en el exterior —en un animal compañero, en un monte-. Además, algunas esencias abandonan el cuerpo después de la muerte y llegan a algún destino final, mientras que otras se quedan en el plano terrenal, en los restos o en las pertenencias de los difuntos (López, 1980;

\footnotetext{
${ }^{3}$ Quisiera aclarar que la cacería lacandona en las milpas no corresponde al modelo de la "milpa comedero-trampa", una técnica empleada en varios grupos mayas (véase Santos-Fita, et al., 2013). En el caso analizado por SantosFita (2013), los mayas yucatecos designan determinados espacios agrícolas para atraer a las presas y capturarlas, conceptualizando así el campo como una "trampa". Pero con respecto a los lacandones, como ya fue señalado, la caza es un evento casual: al encontrar un animal en su milpa el campesino puede abatirlo y luego consumirlo; también, si un determinado animal se presenta varias veces en el campo, pueden tenderse trampas para capturarlo e impedirle dańar los cultivos. No obstante, no hay espacios de áreas agrícolas creados expresamente para la captura de animales.
}

EntreDiversidades. Revista de Ciencias Sociales y Humanidades, Vol. 8, Núm. 2 (17), julio-diciembre 2021. Páginas: 30-55 ISSN-e: 2007-7610. https://doi.org/10.31644/ED.V8.N2.2021.A02 
Martínez, 2007; Velásquez, 2009). Las almas que pertenecen a esta segunda clase, y que nos conciernen en este ensayo, pueden encerrar una doble naturaleza, en razón de su permanencia e indestructibilidad: pueden considerarse como factores de fertilidad que permiten la regeneración del cuerpo o la continuidad generacional; o bien, se conceptualizan como entidades obstinadas y perversas que se mantienen en el plano terrenal, causando todo tipo de desgracias a los seres vivos (Guiteras, 1965: 130 y 153; Petrich, 2007: 150; Pitarch, 2013: 59). Estas “almas" presentan las mismas características de sus soportes orgánicos (huesos, uñas, cabello): no desvanecen después de la muerte y permanecen entre los vivos. Como se verá más adelante, la peligrosidad que se les atribuye a los "huesos sin carne" (Pitarch, 1996: 76) explicaría el porqué de los cuidados que deben observarse al manejar los restos mortales de humanos y animales. Además, otra razón fundamental es la propiedad fértil atribuida a los huesos, señalada por diversos autores que han trabajado entre los mayas: el término baak, que indica los huesos en las antiguas inscripciones (Houston, Stuart y Taube, 2006: 31), se encuentra en varias lenguas mayas contemporáneas y puede traducirse también como "semilla", o bien hace referencia a otros elementos vegetales. Lo anterior se observa entre los tojolabales estudiados por Lenkersdorf: en el vocabulario tojolabal-español se menciona que el término b’ak se traduce como "hueso" y forma parte de términos que pertenecen al campo semántico de varios elementos óseos (esqueleto, calavera, cráneo), así como en la expresión teb’akal, "olote" ${ }^{4}$ (2010: 160). Así, el término homófono b’ak’ puede traducirse como "semilla, testículo o fruto" (Lenkersdorf, 2010: 161). Del mismo modo, en el área k’iché los huesos se conciben como semillas que poseen fuerza y vida de forma latente (Carmack, 2018: 284). De hecho, Scherer señala que en lengua k'iché el término "huesos" se traduce como baq, homófono con baq', palabra que significa "semillas" (2015: 94). Carlsen y Prechtel evidencian las correspondencias entre las concepciones agrarias y escatológicas de los atitecos, quienes definen a las semillas de maíz con el término muk (los enterrados) o jolooma (pequeñas calaveras), lo que indica que la vida brota del plano telúrico, como las semillas de maíz que son "enterradas" antes de convertirse en plantas para volver así a la luz (1991: 28). Se trata de una concepción ubicua entre los mayas, como lo evidencia Girard:

Hay íntima vinculación entre lo agrario y lo escatológico. La posición del grano del maíz en el seno de la madre-tierra se asimila a la del nińo en el claustro materno, y a la de un muerto en la tumba [...] En las oscuras regiones del inframundo, la semilla, como el cadáver y como el feto, luchan contra fuerzas adversas para surgir en un mundo nuevo [...] (1962: 156).

De acuerdo con Scherer, entre los mayas antiguos los huesos estaban cargados de profundos significados simbólicos, en cuanto a que representan el elemento más perdurable (e imperecedero) del cuerpo humano. Por consiguiente, los restos óseos eran una evidencia de la inevitabilidad de la muerte, pero también simbolizaban la fertilidad y la posibilidad de una nueva vida (2015: 94).

Esta lógica se inserta en la concepción maya sobre la muerte, que representa una fase del ciclo vital, una condición necesaria para la generación de la vida (Ruz, 1991; Carlsen y Prechtel, 1991; Ciudad, Ruz y Ponce, 2005). En este sentido, es necesario recordar que también en el Popol Vuh se

${ }^{4}$ Corazón de la mazorca de maíz.

EntreDiversidades. Revista de Ciencias Sociales y Humanidades, Vol. 8, Núm. 2 (17), julio-diciembre 2021. Páginas: 30-55 ISSN-e: 2007-7610. https://doi.org/10.31644/ED.V8.N2.2021.A02 
acude a la metáfora frutos/huesos, maíz/huesos, para indicar un proceso de regeneración (Sotelo y Craveri, 2017). Un ejemplo lo encontramos en la historia de Hun Hunahpú. Los Señores de Xibalbá creyeron haber aniquilado al héroe (Hun Hunahpú) y a su hermano, pero la calavera del primero colgada de un árbol de jícaro acaba fecundando milagrosamente a la joven Xquíc con su saliva. Esta es la primera derrota simbólica de las fuerzas oscuras del inframundo, gracias a las propiedades fértiles de los restos óseos de Hun Hunahpú. Del embarazo de Xquíc nacen los Hermanos Gemelos (Hunahpú y Xbalanqué), que serán protagonistas de otro momento emblemático representado por su supuesta derrota. Tras ser asesinados por los Señores de Xibalbá, sus huesos son "molidos como granos de maíz" y arrojados a un río. Cuando los Señores piensan haber derribado a los jóvenes, estos vuelven a nacer de sus restos y aniquilan a sus oponentes (Sotelo y Craveri, 2017: 122-123). Así, los huesos molidos simbolizan las semillas que regresan a la vida para una nueva generación, convirtiéndose en la metáfora de la vida que brota de la muerte y que, por lo tanto, la anulan.

La profunda significación simbólica atribuida a los huesos se manifiesta en un amplio conjunto de prácticas religiosas, como lo demuestran los estudios relativos al manejo de los despojos humanos en el área maya: el empleo de los huesos de los ancestros para conjuros (Fitzsimmons, 2009; Scherer, 2015), la limpia de huesos, la conservación de los despojos en los bultos sagrados, los funerales secundarios (Eberl, 2005; Fitzsimmons y Fash, 2005; Maza, 2009; Romero, 2017) y la preservación de las reliquias de personajes de relieve o cautivos como herramientas de poder (Fitzsimmons, 2009; Scherer, 2015). Todas estas prácticas demuestran el valor mágico y simbólico atribuido a los huesos (Fitzsimmons, 2009: 75; Schele y Freidel, 2011: 156; Ruz, 1991, entre otros). No se ahondará en la descripción de estos procesos rituales, ya que existe abundante bibliografía al respecto, aunque sí se introducen las significaciones simbólicas del elemento hueso para poder explicar los ritos de cacería que nos conciernen. De hecho, se evidencian claras correspondencias entre las creencias señaladas y las concepciones sobre el cuerpo presentes en las sociedades nativas cazadoras, en las que los restos de las presas están sujetos a ritos de conservación o devolución, por lo que no se expresa una diferencia substancial entre el cuerpo animal y el cuerpo humano (Lévi-Bruhl, 1985 [1927]: 184; Frazer, 1944 [1890]: 598; Århem, 2001: 285-286; Fausto, 2002: 10-17; Lot-Falck, 2018 [1953]: 186-187). Hamayon, quien estudia la cacería entre los pueblos siberianos, argumenta que, mientras que las carnes de las presas se descomponen, los huesos representan la parte más imperecedera del organismo y, por lo tanto, fungen como soporte para determinadas esencias anímicas (2009: 32). Estas se convierten en un principio vital latente que descansa en los huesos, hasta que los intermediarios indicados — los dueños de la fauna o las deidades — los reciclen para darle vida a otros seres, que reemplazarán a aquellos que fueron sacrificados. De este modo, la autora aclara que el compuesto espiritual que yace en los huesos está presente tanto en los seres humanos como en los animales:

Esta concepción será aquí, por convención y falta de una mejor, dada por la noción de re-nacimiento. Esta disociación entre cuerpo y hueso funda el tratamiento funerario de los animales y de los humanos. El mismo objetivo es, en efecto, referido para unos y para otros: liberar la carne para devolverla consumible por el prójimo, y permitir al hueso servir de soporte

EntreDiversidades. Revista de Ciencias Sociales y Humanidades, Vol. 8, Núm. 2 (17), julio-diciembre 2021. Páginas: 30-55 ISSN-e: 2007-7610. https://doi.org/10.31644/ED.V8.N2.2021.A02 
simbólico a un nuevo ser de mismo linaje o misma especie, a modo de perpetuar su doble relación, de intercambio y de alianza. Estas relaciones son concebidas bajo el modelo de las relaciones de los humanos entre ellos; éstas reposan sobre la idea de que el cuerpo animal está "animado" por un compuesto espiritual de la misma naturaleza y del mismo estatus que aquel que anima al cuerpo humano. Se supone que este componente espiritual o "alma" reside en los huesos tanto entre los humanos como entre los animales (Hamayon, 2009: 32).

Este principio de vitalidad conservada en los huesos justificaría los tratamientos rituales de los despojos de las presas, observables en numerosas sociedades del mundo, como lo demuestran la multitud de casos etnográficos citados por Frazer a lo largo de su recopilación (1944 [1890]: 598). Lo mismo ocurre en el contexto amazónico, donde la cacería y las relaciones entre humanos y no-humanos cobran importancia crucial (Århem, 2001: 285-286; Fausto, 2002: 10, 17), así como en Mesoamérica (Dehouve, 2008: 18; Neurath, 2008: 27; Osorio-López, et al., 2017: 58). En lo concerniente a los mayas, anteriormente se mencionaron los datos arrojados por Brown y Emery, quienes analizan los depósitos de los restos de las presas en las cuevas de Guatemala y aclaran que este proceso tiene como finalidad permitir la regeneración de las especies cazadas (Brown, 2005, 2009; Brown y Emery, 2008). De hecho, Braakhuis (2001), en un interesante ensayo, argumenta que los mitos mayas atribuyen al cazador un papel clave en la regeneración de los huesos del venado: el depósito de los restos de las presas en las cavidades naturales, morada de los dueños de la fauna, es un proceso ritual que permite a estos procrear nuevos animales a partir de los restos de aquellos que fueron sacrificados. Cada grupo étnico establece de qué manera se debe disponer de los restos de las presas, pero en ningún caso estos son considerados elementos inertes o desechables. Es interesante notar que también Lot-Falck asocia los huesos con elementos vegetales, con semillas y brotes, y menciona el ejemplo de los kamchadales de Rusia, quienes dispersaban los restos de las focas en el mar para que de ellos pudieran nacer nuevas criaturas:

De este modo, el cuerpo de una sola foca producirá una vasta progenie. De la misma manera se multiplican las yemas a partir de un único tronco, y nuevas plantas a partir de las semillas. Los restos de la caza, solemnemente devueltos al mar, al final de las grandes ceremonias de las tribus marítimas, volverán a la vida en el elemento restaurador, sin que se necesite la intervención divina. Los restos se entregan al mar, así como las semillas a la tierra, que los fecundará (2018, [1953]: 187, traducción propia).

El paralelismo entre las concepciones relativas a los despojos humanos y animales queda así reafirmado. En el siguiente párrafo, se discutirá sobre la prohibición de quemar los huesos, tema central del presente escrito. Se buscarán las justificaciones de este tabú acudiendo a un breve análisis relativo a las ideas sobre el elemento ígneo y al concepto de fertilidad entre los mayas. Donde sea pertinente, se recurrirá también a datos procedentes de otros contextos culturales.

EntreDiversidades. Revista de Ciencias Sociales y Humanidades, Vol. 8, Núm. 2 (17), julio-diciembre 2021. Páginas: 30-55 ISSN-e: 2007-7610. https://doi.org/10.31644/ED.V8.N2.2021.A02 


\section{Fuego, cremación e inframundo}

Joel Palka, en su estudio sobre la cremación simbólica entre los lacandones, menciona que en distintas sociedades del mundo el fuego es considerado como un componente fundamental del cosmos, en cuanto permite la transformación de los elementos, así como su purificación (2018: 302). Para los mayas, el fuego es "una potencia sagrada y uno de los elementos creadores del cosmos, así como responsable de su revitalización y continuidad" (Nájera, 2019: 119). Es una fuerza purificadora, creadora, fecundadora, fundacional y protectora, por lo que fue un importante objeto de culto, especialmente en el Periodo Clásico (2019: 93; véase también Craveri, 2012: 51).

Sin poder ahondar demasiado en el tema, cabe mencionar que en el pensamiento maya la combinación entre fuego y agua virgen se consideraba esencial en los ritos llevados a cabo para propiciar la fertilidad:

El fuego representaba el axis mundi que concretizaba la comunicación entre los diversos polos del cosmos y el instrumento que, por lo tanto, permitía una transformación; el agua, fuente subterránea, pero también de la superficie, era el elemento que, favoreciendo la germinación y la salida a la superficie de las plantas y, sobre todo, del maíz, se convertía en agente simbólico del renacimiento (Peretti, 2015: 11).

Nájera define la fertilidad como "una energía sagrada que les permitiría [a los hombres] la continuidad de su existencia y de todo lo que para ellos era apreciado" (2002: 126). Así, la autora menciona el ritual de tup k'ak, también descrito por Landa (1986 [1959]), en el cual se arrojaban a una hoguera corazones de pequeños animales y luego las flamas se apagaban con grandes cántaros de agua, uniendo así el poder del fuego con el del agua virgen (Nájera, 2002: 117). Este rito era precedido por otro ritual, el de cháa cháak; la combinación de estos dos rituales tenía la finalidad de propiciar la lluvia para la siembra (Meehan, 2013: 37). Ambos aún se celebran entre los mayas peninsulares, de los que se encuentra una descripción detallada en la tesis de Lázaro Tuz Chi (2009), quien realizó trabajo de campo en Tiholop, Yucatán.

Con respecto al agua virgen ( $z$ uhuy ha), este elemento era fundamental en los ritos de fertilidad, además, la importancia otorgada a las cuevas se origina también en el hecho de que constituían fuentes para el aprovisionamiento del líquido sagrado (Thompson, 1982 [1975]: 230-231). Tampoco es posible soslayar la importancia del fuego y del agua en el contexto agrario (Craveri, 2012: 52), como también lo expone Morales:

El fuego es un elemento esencial en la configuración de la vida social de una comunidad agraria: produce calor, protege de depredadores y es un medio para procesar el alimento, no es extraño que sea un importante símbolo religioso. En el caso de la agricultura maya, como hemos anotado previamente, el fuego resulta imprescindible pues el sistema de cultivo inicia con la tala diferencial de una parte del bosque que se deja secar para luego incendiarlo, las cenizas servirán de abono y prepararán al terreno para la siembra (2014: 179).

EntreDiversidades. Revista de Ciencias Sociales y Humanidades, Vol. 8, Núm. 2 (17), julio-diciembre 2021. Páginas: 30-55 ISSN-e: 2007-7610. https://doi.org/10.31644/ED.V8.N2.2021.A02 
Además del complejo ritual tup k’ak-cha’a cháak ya mencionado, entre los mayas de Yucatán se emplea el fuego para purificar y preparar los huertos domésticos antes de la siembra, a través de un ritual llamado jeets' lu'um (calmar la tierra), que se celebra en un espacio agrícola familiar. Este tiene la finalidad de limpiar el terreno de los malos espíritus o vientos malignos y propiciar así las siembras (Harald, 2010: 37).

A pesar de lo que se ha expuesto, en el presente apartado se argumentará que, con respecto a los despojos humanos y animales, la cremación se considera peligrosa o, en muchos casos, se prohíbe. Una vez, pregunté a un informante por qué no está permitido quemar los restos de las presas, y este me contestó que "quemar huesos es cosa del demonio", una aserción que encuentra varios correspondientes en las creencias de los mayas contemporáneos, como se argumentará a continuación.

En primer lugar, es necesario abrir un paréntesis sobre la cremación en el área maya. Alberto Ruz Lhuillier (1991) aclara que, tanto en la cultura maya como en las del centro de México, se practicaban la inhumación y la cremación. Sin embargo, los aztecas enterraban exclusivamente a las personas fallecidas por enfermedades contagiosas, a las parturientas difuntas o a aquellos que habían sido matados por los rayos, mientras que la cremación era la forma usual de disponer de los cuerpos. Por el contrario, entre los mayas la cremación era destinada exclusivamente a los nobles y la gente común recibía entierro (1991: 76-77; véase también Webster, 2006: 4).

En el transcurso de sus exploraciones en tierras mayas, Frans Blom (1954) encontró urnas cinerarias en varias cuevas; dichos entierros se realizaron principalmente en el periodo Posclásico. En Chiapas, el arqueólogo halló diversas urnas cinerarias en Tzajalob, en la cueva de Cineguilla, y en Rosario Trabajo. En particular, en esta última descubrió una urna con cenizas y un vidrio veneciano, lo que indicaría que la costumbre de incinerar a los difuntos estaba aún vigente al tiempo de la Conquista en Chiapas (Blom, 1954: 129-130). La descripción de los ritos funerarios proporcionada por Landa, parece confirmar lo anterior:

A los señores y gente de mucha valía quemaban los cuerpos y ponían las cenizas en vasijas grandes, y edificaban templos sobre ellas, como muestran haber hecho antiguamente los que se hallaron en Izamal. Ahora, en este tiempo, se halló que echaban las cenizas en estatuas huecas, hechas de barro, cuando (los muertos) eran muy señores (1986 [1959]: 59).

Cabe reiterar que en el área maya la cremación se introdujo posteriormente, cuando los grupos mexicanos invadieron el norte de Yucatán y los altos de Guatemala. De este modo, se difundió en el Posclásico Tardío y, aun así, siguió reservándose para personas que gozaban de alto rango (Palka, 2018: 292). En todo caso, nunca fue el método primario de disposición de los cadáveres, quedando la inhumación como la práctica más difundida (Ruz, 1991, Webster, 2006).

Algunos autores infieren que la creencia en las propiedades fértiles de los huesos podría explicar por qué la práctica de la cremación no gozó de larga difusión. En general, se cree que las instancias anímicas de un ser fallecido se vuelven peligrosas y pueden perjudicar a los vivos. Se trata de una concepción muy difundida en Mesoamérica, donde se piensa que las "almas" de los difuntos pueden volverse "aires malos" o "espíritus dañinos" (Guiteras, 1965: 130, 153;

EntreDiversidades. Revista de Ciencias Sociales y Humanidades, Vol. 8, Núm. 2 (17), julio-diciembre 2021. Páginas: 30-55 ISSN-e: 2007-7610. https://doi.org/10.31644/ED.V8.N2.2021.A02 
Petrich, 2007: 150; Pitarch, 2013: 23-24). Lo anterior explicaría por qué se evitaba quemar los huesos: la acción del fuego libera y dispersa las esencias anímicas de manera rápida y violenta, volviéndolas peligrosas para los vivos. Además, el fuego invalidaría las propiedades fértiles de los restos óseos, como lo señala Lot-Falck: "En el folklore de varios pueblos, está difundida la creencia de que es posible revivir a un ser si sus huesos quedan intactos. Quizá esta sea una de las razones subconscientes que alejaron muchos pueblos de la cremación” (2018 [1953]: 188, traducción propia). También entre los lacandones el elemento ígneo puede considerarse peligroso, en cuanto "si quemas al hueso del muerto sale el kisin ok, el 'demonio del pie', que sale rápido, y es peligroso" (Entrevista a don Chankin P., Nahá). Cabe aclarar que el kisin ok es la esencia anímica que permanece en los despojos de los difuntos y de los animales; se piensa que es capaz de enfermar a las personas con las que entre en contacto (Baer y Baer, 1950: 259; Boremanse, 2020: 209). Por esta razón, los lacandones, además de evitar quemar los restos óseos, se abstienen de frecuentar el panteón. La presencia de esta entidad anímica explicaría por qué los lacandones no incineran los cuerpos de sus difuntos. Joel Palka (2018) reporta algunos casos de cremación que se registraron entre los antiguos lacandones, no obstante, se trata de casos peculiares que podrían considerarse excepciones.

De acuerdo con Barrera y Antochiw (apud Palka, 2018: 303), por el ańo 1817 un cura de Guatemala, el Fraile Manuel de la Chica, quien había establecido una buena relación con los lacandones, fue asesinado por un mestizo. Los lacandones decidieron quemar sus restos y echarlos a un río. En este caso, se observa que la cremación fue destinada a un extranjero, además, es plausible que consideraran al cura como un personaje importante, debido a su papel de líder religioso, y que por esta razón no se enterrara. Una mención a la cremación entre los lacandones coloniales se encuentra en la obra etnográfica de los Baer, quienes hablaron con el líder de los lacandones de aquel tiempo, Chan K'in Viejo, el cual les dijo que: "se quemaban los cuerpos para liberar el alma”, pero que "al escuchar llegar un alma, ellos se asustaban y huían”. Los autores concluyen que, al parecer, esta fue la razón por la cual los lacandones abandonaron dicha práctica (Baer y Baer, 1950: 221).

Romero Sandoval analiza las concepciones prehispánicas sobre el inframundo, haciendo referencia a las descripciones proporcionadas por Landa o contenidas en otros textos coloniales, donde no se menciona el fuego como elemento característico del plano telúrico, sino que este es descrito como un espacio oscuro y frío. Así, de acuerdo con el autor, el frío es un elemento característico del inframundo mesoamericano (2017: 27). Cabe recordar que la morada de los difuntos se presenta como un ámbito diametralmente opuesto al espacio humano y que entre los mayas el concepto de calor se asociaba al astro solar, a la vida, y se consideraba una cualidad de la existencia misma (Bassie-Sweet y Hopkins, 2018: 55). Quizá por esta razón, en concepto de algunos pueblos mayas contemporáneos, el inframundo es un lugar caracterizado por oscuridad y ausencia de calor, en el que se queman los huesos de los humanos fallecidos, que serían la "leña" con la que se calientan los seres ctónicos (Pitarch, 1996: 53). En los Altos de Chiapas, otra manera de llamarle al inframundo es Kajktimb'ak, literalmente "calentar con huesos" (Guiteras, 1965; Medina, 1991). Vogt lo define como un "lugar calentado por huesos" y lo describe como un hoyo profundo, en el interior de la Tierra (1979: 31).

EntreDiversidades. Revista de Ciencias Sociales y Humanidades, Vol. 8, Núm. 2 (17), julio-diciembre 2021. Páginas: 30-55 ISSN-e: 2007-7610. https://doi.org/10.31644/ED.V8.N2.2021.A02 
En muchos relatos indígenas se especifica que lo que los vivos ven como despojos de seres humanos sería en realidad la leña de los moradores del bajo mundo. Laughlin recolectó distintos mitos entre los zinacantecos de Los Altos de Chiapas, donde se encuentra esta alusión; así, un hombre visita a su esposa en el más allá, y cuando la mujer le pide que vaya a buscar leña para prender el fuego, él no ve nada más que huesos amontonados:

“¿Cómo vamos a prender la leña para el fuego?”, preguntó.

“Oh, ¡vámonos!”, dijo. "Lo que debes de buscar son huesos podridos, no la verdadera leña para el fuego", dijo la mujer. [...]

Empezó a buscar la leña. Pero se trataba solo de huesos, huesos podridos que calentaban los espectros de aquellos que [habían cometido] los peores crímenes. Esta es la razón por la cual se le llama [al infierno] "calentar con huesos" [k’atin-bak] (Laughlin, 1977: 28-29, traducción propia). ${ }^{5}$

En un relato tseltal se cuenta cómo un hombre pudo conocer el más allá, tras haber encontrado un misterioso caballero ladino montado en un caballo negro, que lo acompańó al bajo mundo. Allí, el personaje misterioso — una encarnación del Señor del inframundo- le pidió al tseltal que fuera a buscar leña para el fuego, pero, también en este caso, el hombre no vio nada más que huesos apilados (Ávalos y Guzmán, 1985: 279). En otro cuento tojolabal, El Sombrerón y la Mula, se narra la historia de un hombre que baja al inframundo para buscar a su esposa difunta, el Pukuj (o Sombrerón) lo acompaña y le muestra a su mujer convertida en una mula. Este personaje, que es el dueño del inframundo, le pide al hombre que vaya a rajar leńa, pero aquel solo ve pilas de huesos (La Chica, 2017: 349).

En la narrativa lacandona, es Nuxi el ancestro que desciende al Metlan ${ }^{6}$ y regresa con vida a la selva para contar sus vivencias a sus compañeros (véase Bruce, 1974; Boremanse, 2006; Cook, 2019). El protagonista del mito es también llamado $\ddot{A} h$ u Lejibaj, "el atrapa-topos”. Se trata de un cazador que tras haber exterminado sin piedad un gran número de topos es hechizado por la bella hija de Kisin, ${ }^{7}$ protectora de las tuzas. La muchacha invita el hombre a perseguirla, seduciéndolo con su belleza, y lo lleva hasta el reino de Kisin, pasando por una cueva que conduce al hogar del Causante de la Muerte. Allí, el cazador aprende cuál es el destino de las almas que llegan al más allá (Boremanse, 2006: 69-92). Decide casarse con la hija de Kisin y presta servicio en la casa de su suegro, en donde se percata de los hábitos alimenticios repugnantes de los "demonios". Su esposa y su suegro le ofrecen varios tipos de alimentos, que a los ojos de los kisin son tortillas,

\footnotetext{
5 "We are supposed to go haul the firewood?", he said. / "Oh, let's go", she said. "It's the rotten bones you should look for, not the real firewood", said the woman [...] / He looked for firewood. But it was just bones, rotten bones for warming the ghosts who [had committed] the worst crimes. That's why [Hell] is called "warmed by bones" [k'atin-bak] (Laughlin, 1977: 28-29).

${ }^{6}$ El Metlan es el inframundo de los lacandones, en maya yucateco se llama Metnal, término derivado de Mictlán, nombre náhuatl del inframundo (Thompson, 1982 [1975]: 363-364).

${ }^{7}$ Kisin es el dios malvado y caprichoso que rige el Metlan, es también llamado "el Temblor" o "El Causante de la Muerte", y se considera como la causa de varias desgracias que afectan a los seres humanos. Su hija es la protectora de las tuzas, su nombre es mencionado solo por Boremanse (2006: 82): X-Baakel (Ella-de los huesos).
}

EntreDiversidades. Revista de Ciencias Sociales y Humanidades, Vol. 8, Núm. 2 (17), julio-diciembre 2021. Páginas: 30-55 ISSN-e: 2007-7610. https://doi.org/10.31644/ED.V8.N2.2021.A02 
frijoles y atole, pero que, en realidad, son cadáveres putrefactos, moscas y larvas (Cook, 2019: 160-162). A su vez, se encuentra el elemento de los huesos utilizados por los kisin como leńa para el fuego (Boremanse, 2006: 84). En palabras de una mujer de Nahá: "La leña del fuego era el esqueleto, para ellos lo que es leña es hueso, nuestros huesos, y lo que es frijol era mosca, era pura mosca, salió volando. Y el chile era puro gusano y la tortilla era carne podrida" (Entrevista a Koj, Nahá).

También en el Popol Vuh se asocia el ocote de Xibalbá con los huesos: "[...] su ocote era una punta redonda de pedernal del que llaman zaquitoc; éste es el pino de Xibalbá. Su ocote era puntiagudo y afilado y brillante como hueso; muy duro era el pino de Xibalbá" (Recinos, 1993: 55). Scherer se pregunta si esta concepción se originó después de la introducción del concepto cristiano de infierno, no obstante, el autor muestra que en la teología cristiana no hay ninguna referencia explícita al hecho de que en el Infierno se quemen huesos (2015: 47), por el contrario, esta idea parece haber estado presente entre los antiguos mayas. Por ejemplo, en una vasija procedente del Periodo Clásico se puede apreciar un dios de la muerte (probablemente Ah Cizin) sentado enfrente de una hoguera de huesos cruzados (2015: 47). Así, Scherer infiere que la imagen del Inframundo como un lugar donde arden los huesos podría haberse generado de la observación de que determinadas enfermedades, difundidas entre los mayas antiguos, causaban ardor de huesos. De ahí la asociación del Inframundo — lugar de enfermedades y sufrimientos - con los huesos quemados (2015: 54).

Sea como fuere, se observa que la quema de despojos humanos es generalmente atribuida a los Señores del Inframundo. No se puede olvidar que, en el Popol Vuh, cuando los Hermanos Gemelos son supuestamente derrotados, los Señores de Xibalbá discuten sobre la manera más efectiva de liberarse de sus despojos. Cabe aclarar que los Señores querían aniquilarlos, aunque su intento resultara en vano, ya que los muchachos volvieron a nacer. Sin embargo, como medio para la destrucción de los despojos de los jóvenes se elige el fuego. De hecho, los Señores se reúnen para decidir qué hacer con los huesos de los Gemelos. Uno propone echar los restos al barranco, pero otro le contesta: "No estará bien, solamente luego se despertarían sus rostros". Otro se pregunta si colgar los huesos a los árboles, pero también se descarta esta opción, ya que: "veríais otra vez sus rostros". Finalmente, los Señores deciden moler los huesos como maíz: "fue preparada una gran piedra ardiente, así como una hoguera hicieron los de Xib'alb'a, grandes tiznes le pusieron [...] —Os vamos a quemar- dijo el señor [...]" (Sotelo y Craveri, 2017: 122-123). Se puede interpretar este pasaje a la luz de los datos que se muestran en el presente escrito: los huesos retienen la propiedad anímica de sus dueños, por lo tanto, si se conservan, pueden garantizar la resurrección del sujeto. En efecto, los Señores de Xibalbá ya habían fracasado en el intento de aniquilar a uno de sus oponentes, cuando colgaron la cabeza de Hun Hunahpú al árbol y su calavera conservó sus propiedades fértiles, fecundando así a Xquíc. A través de la calavera intacta, Hun Hunahpú pudo asegurar su continuación mediante su progenie (2017: 69-75). En el caso de Hunahpú y Xbalanqué, es cierto que los hermanos resurgen a pesar de que los huesos fueron quemados, pero se puede inferir que la conservación de las propiedades fértiles fue posible en cuanto la acción del fuego se combinó con la del agua del río. De hecho, Craveri argumenta que, en este caso, el elemento ígneo representa un medio de transición, que permite la transformación

EntreDiversidades. Revista de Ciencias Sociales y Humanidades, Vol. 8, Núm. 2 (17), julio-diciembre 2021. Páginas: 30-55 ISSN-e: 2007-7610. https://doi.org/10.31644/ED.V8.N2.2021.A02 
de los Héroes (2012: 51). De este modo, es posible volver al paralelismo entre lo escatológico y lo agrario: el fuego es esencial para que el maíz pueda nacer, pero lo que se quema y purifica es el terreno, no las semillas. Como fue aclarado, el fuego sana y prepara la tierra, pero sin la acción del agua (la lluvia) las plantas no podrían nacer de las cenizas. Como se vio en el apartado anterior, se estableció el paralelismo entre las semillas y los huesos, de esta manera, quemar los huesos sería equivalente a quemar las semillas, es decir, despojarlos de sus propiedades anímicas, de su esencia fértil y portadora de vida. Como será demostrado a continuación, la quema de los huesos de las presas se considera inaceptable en diferentes sociedades cazadoras.

\section{La prohibición de quemar los huesos de las presas: material etnográfico y análisis}

Ya se mencionó que la necesidad de preservar los huesos de los animales se registra en numerosas sociedades cinegéticas, en distintos contextos geográficos (Lot-Falck 2018 [1953]; Århem, 2001; Fausto, 2002; Dehouve, 2008; Hamayon, 2009, entre otros). Después de haber analizado las nociones mayas sobre los elementos óseos y el ciclo vital, es de asumirse que, también para el caso de las presas, la cremación se considera como una práctica peligrosa y, por consiguiente, debe evitarse o prohibirse (véase Frazer, 1944 [1890]: 596-597).

Las siguientes entrevistas recabadas en campo ayudan a analizar las concepciones lacandonas sobre la quema de los restos de las presas: ${ }^{8}$

A: - Yo vi que no quemas los huesos de los animales, que los juntas...

C: - Los junto, los dejo en el tronco de un árbol.

A: - ¿Por qué?

C: - Su dueño no quiere, no está bien quemar, también se va a morir tu perro, los huesos de los brazos de los monos arañas los tienes que juntar, esos son muy grandes, si yo me muero, mi esposa me dará esos huesos, los tomaré.

A: — ¿Y los huesos de las cabezas?

C: - Esos los junto, en el tronco de un árbol o en una cueva los llevo.

A: - ¿Por qué?

C: - Allí está el dueño de los animales, aquel que cuida a los animales

A: - ¿Cómo se ve?

C: —iEs gente! (Hach Winik), tiene su sak nok (túnica) (Entrevista a don Chan K’in P., Nahá,

12 de abril de 2019).

A: - ¿Por qué me dijeron que no es bueno quemar los huesos de un animal? Si por ejemplo comes a un tepezcuintle, ¿por qué no puedes quemar sus huesos?

$\mathrm{K}:$ - Si quemas sus huesos, no volverás a matar, da lástima que quemas los huesos, no puedes quemar...

A: —¿Dónde los pones?

C: - En la selva, o si tienes un perro se los puedes dar [...], solo no los quemes.

A: —¿Quién se enojaría?

${ }^{8}$ Se presenta la traducción de los fragmentos de dos entrevistas, las frases en cursivas fueron pronunciadas en español.

EntreDiversidades. Revista de Ciencias Sociales y Humanidades, Vol. 8, Núm. 2 (17), julio-diciembre 2021. Páginas: 30-55 ISSN-e: 2007-7610. https://doi.org/10.31644/ED.V8.N2.2021.A02 
C: -Tienen su dueño, son los animales domésticos de alguien, por ejemplo de K’änänk’ax [el Guardián de la Selva], esos son sus animales domésticos, como gallina, tiene dueño la gallina, tiene dueño, si no pides permiso para agarrar, sus animales domésticos nunca los volverás a ver, si vas a buscarlos, no volverán a salir.

A: - ¿Y si mato a muchos animales?

C: - Te va a castigar, si matas a muchos. Ah... su dueño te espanta [literalmente: "te golpea el alma”] (Entrevista a don K’in, Nahá, 16 de mayo de 2019).

Como se puede leer en los testimonios, los dueños de la fauna no toleran que los restos de sus protegidos sean quemados; ya se explicó que la cremación es incompatible con la conservación de las propiedades fértiles de los huesos, por lo que debe ser evitada. Los dueños consideran a las presas como sus animales domésticos, una creencia difundida en otros pueblos mayas (Thompson, 1930: 141-142; Guiteras, 1965: 142; Villa, 1992: 295; Köhler, 2007: 139-141; Herrera-Flores, et al., 2018: 10, entre otros).

Esta es la razón primaria que justifica la necesidad de devolver los restos de los animales sacrificados: como todo lo que se halla en la naturaleza, también las presas son consideradas como una pertenencia de las instancias divinas, así, convertirlas en un recurso para el consumo implica el respeto a determinadas reglas, entre las que destacan la devolución y la conservación de sus restos mortales. Evitar quemar los huesos forma parte de las normas que fundamentan el contrato establecido entre los cazadores y los dueños - o dioses-. Los mitos lacandones codifican estas normas (Boremanse, 2006) y "esa relación con el doble propósito de normalizar los intercambios materiales que unen objetivamente el hombre con su entorno, y de establecer los vínculos de reciprocidad que unen espiritualmente a los humanos con las creaciones mentales de su universo fantasmagórico" (Marion, 1991: 148). ${ }^{\text {? }}$

Los dueños sancionan a los hombres irrespetuosos de maneras diferentes; el castigo más blando consiste en impedir al cazador el éxito en sus futuras empresas cinegéticas. O también, pueden "espantar al culpable", una expresión que en maya lacandón se traduce como $u$ hatzik $u$ yor (golpear su alma), es decir, extraer el alma de la víctima, para que esta se enferme o muera.

Otra razón de la conservación de los huesos es mencionada en la primera entrevista por don Chan K'in, quien aclara que, cuando muera, su esposa le dará un hueso de mono. A pesar de los cambios culturales, esta costumbre sigue vigente entre los lacandones; al difunto se le entregan tres objetos que ayudarán a que su alma supere las pruebas del inframundo: un mechón de cabello, para los piojos que obstaculizan el tránsito del alma, algunos granos de maíz, para los pollos que forman una barrera infranqueable, y un hueso, para que los perros del Metlan dejen pasar al alma y la ayuden a cruzar los peligrosos ríos del más allá (Bruce, 1974; Boremanse, 2020). En campo se observó que algunos huesos largos, principalmente fémures de monos o venados, se conservan en las viviendas para este propósito.

\footnotetext{
${ }^{9}$ Aunque no estoy de acuerdo con la definición de "deidades" que emplea Marion, elegí esta cita porque explica que también los lacandones conciben las relaciones con los númenes sagrados en términos de reciprocidad. De este modo, aprovechar un "recurso natural", como talar un árbol, quemar plantas para rozar la milpa o matar a un animal, nunca puede ser un acto gratuito.
}

EntreDiversidades. Revista de Ciencias Sociales y Humanidades, Vol. 8, Núm. 2 (17), julio-diciembre 2021. Páginas: 30-55 ISSN-e: 2007-7610. https://doi.org/10.31644/ED.V8.N2.2021.A02 
En la primera entrevista, Chan K'in agrega que los dueños pueden cobrar su venganza sobre los perros, que son muy importantes en las batidas de caza, como también se observa entre los mayas yucatecos (Tuz Chi, 2009) y los cazadores de Guatemala (Brown y Emery: 2008: 310; Brown, 2009: 43-44). De hecho, el perro es considerado como una criatura dotada de sentidos especiales, capaz de ver el mundo invisible y proteger a sus dueños de las amenazas de los espíritus (Plata, et al., 2019: 9). La importancia de los perros en las batidas de caza no se limita a su función práctica como buscadores de presas; puesto que la caza es un acto ritual, también ellos forman parte de este sistema, convirtiéndose en agentes activos. Brown describe los rituales de devolución de los huesos en las cuevas, durante los cuales los cazadores se presentan formalmente a los dueños de la fauna pronunciando sus nombres, así como también los de sus perros, para que estos "los conozcan" (2009: 43-44). En esas ocasiones, los cazadores devuelven los huesos, ofrecen copal y encienden velas, con el propósito de pedir perdón por la sangre derramada. Dado que los perros son parte activa en las batidas de caza, también se consideran "culpables" y es necesario pedir disculpas en su nombre: "en los ritos post-cacería ellos [los perros] son incorporados en las ceremonias, ya que los que participan en el ritual deben de pedir perdón por cada perro, así como por cada humano, involucrado en el derrame de sangre" (Brown y Emery, 2008: 312). Es común que los perros también participen cuando llega el momento de repartir la carne de las presas y, a veces, se les permite comer los huesos más pequeños (Hamayon, 2009: 36).

Entre los lacandones, se piensa que el perro posee una visión especial: se cuenta que, antiguamente, también los hombres gozaban de una mirada divina y se jactaban de tener una vista que llegaba "hasta el infinito". Por esta razón, el dios Hachäkyum decidió quemar sus ojos en un comal, para que perdieran la facultad de ver "las cosas del más allá" (Bruce, 1974: 35-36; Marion, 1999: 130). Se cuenta que, ese día, el perro fue muy listo y se escondió, evitando así el castigo divino y manteniendo una vista excepcional. Los lacandones dicen que los perros son los únicos que pueden ver a Kisin, por lo que cuando ladran de noche están alertando a sus dueños que el Causante de la Muerte o algún espíritu malvado se está acercando. Se trata de una concepción común entre los mayas, quienes piensan que el perro "conoce los caminos en la oscuridad" (De la Garza, 1978: 95) y en muchos mitos acompaña las almas durante su descenso al inframundo. Gracias a sus facultades, este animal protege a los cazadores durante las batidas de caza, ya que la selva es la morada de numerosos espíritus que pueden ser perjudiciales para los seres humanos. Por eso, a estos son entregados algunos huesos y también porciones de la carne. Un joven de Nahá explicó que el perro debe aprender a reconocer el olor y el sabor de sus presas, por eso se les proporcionan algunas partes de la carne, para que se familiarice con el aroma del animal. La entrevista se realizó en español, el uno de enero de 2017, el informante quiso permanecer anónimo. La siguiente cita resume los datos que fueron arrojados en este apartado:

EntreDiversidades. Revista de Ciencias Sociales y Humanidades, Vol. 8, Núm. 2 (17), julio-diciembre 2021. Páginas: 30-55 ISSN-e: 2007-7610. https://doi.org/10.31644/ED.V8.N2.2021.A02 
A: - ¿Por qué no se pueden quemar los huesos?

$\mathrm{C}$ : - Si haces eso, dañas a tu perro cazador. Lo que él caza le tienes que dar su parte, los huesos no se pueden quemar o le quitas su don de cazar, y si cazo sin perro tampoco puedo quemar, porque yo también dejaría de cazar, de encontrar a ese animal, ya no sería un buen cazador. Creo que es su dios de los animales que manda ese castigo, es como yo con mi perro: yo si quemo los huesos le quito su capacidad.

A: - ¿Cómo dices eso en maya?

C: - Ku mäk u ni

A: - Pero eso significa "le tapa la nariz"...

C: - Sí, se tapa. El perro no va a reconocer el aroma de ese animal, es como maltratarlo, es como meterle chile por la nariz o ahogarlo en el humo. Es como lastimar a un perro. Igual los gatos no pueden comer los huesos del animal, debe de ser el perro: tiene que ver su presa y la tiene que comer.

A: - ¿Qué hacen con los huesos de la cabeza?

C: - Se llevan a una cueva, o [si no lo haces] el espíritu del animal te va a seguir toda tu vida. O las puedes tener en la casa, porque allí las guardas, las respetas, no las juegas, es como amar a tu presa. Antes las cabezas también se llevaban al templo.

El hecho de que el perro pueda resultar lastimado o morir puede interpretarse como una forma de venganza de los dueños de los animales, cuando sus "animales domésticos" (las presas) no recibieron un tratamiento adecuado por el cazador, por lo que, como intercambio, exigen la vida del animal doméstico del hombre —o algún tipo de castigo que lo lastime-.

La otra razón por la que se prohíbe quemar los huesos de las presas tiene que ver con el peligro representado por las almas contenidas en los despojos. Ya se anticipó que los mayas piensan que las "almas" arraigadas en los huesos pueden convertirse en entidades peligrosas y que los lacandones creen en la existencia del "demonio del pie" (kisin ok), también llamado "el alma del pie" (Baer y Baer, 1950: 221). De acuerdo con los informantes, esta esencia se encuentra también en los restos de las presas, de manera que se vuelve un agente activo cuando se trata de castigar a un hombre que no respeta las reglas establecidas en la cacería. Es decir, no solamente los dueños pueden sancionar a un hombre irrespetuoso, sino también "las almas de los huesos". De este modo, "si quemas a un hueso de animal, su espíritu te perseguirá toda tu vida, a ti o a tu familia" (Entrevista a C.M., Nahá, enero de 2017). Una vez liberado de la manera equivocada, a través del fuego, el kisin ok se dispersa y puede cobrar su venganza sobre el cazador o sus seres queridos.

Para finalizar este apartado, se mencionará otro caso etnográfico que resume las concepciones lacandonas relativas al efecto del elemento ígneo sobre los restos humanos y animales. En campo, ${ }^{10}$ los informantes comentaron que algunas personas que cometen incesto son convertidas por castigo divino en armadillos y condenadas a vivir en la selva. Se trata de un animal peculiar, al que se le llaman U pixan winik (El alma de un hombre). Este se presenta como un armadillo

${ }^{10}$ Los datos que aquí se presentan no pudieron refrendarse con información bibliográfica, puesto que en ningún trabajo se encontró mención a este peculiar caso: un armadillo silvestre que sería en realidad una persona "atrapada" en el cuerpo de un animal.

EntreDiversidades. Revista de Ciencias Sociales y Humanidades, Vol. 8, Núm. 2 (17), julio-diciembre 2021. Páginas: 30-55 ISSN-e: 2007-7610. https://doi.org/10.31644/ED.V8.N2.2021.A02 
(w’ech), pero posee ojos y manos humanas. Cuando se preguntó a un informante cómo se podía distinguir entre un armadillo común y un "alma de hombre", contestó lo siguiente: "Lo ves que no es normal, por sus ojos y sus manos. Alguien lo quemó [lo capturó y quiso comerlo, sin darse cuenta], quería comerlo asado, pero cuando la carne se puso en el fuego, sus huesos se derritieron, ¡se hicieron como polvo!” (Entrevista a don K., Metzabok, 24 de enero de 2021). Al preguntar la razón por la cual los huesos de la presa se calcinaron, el entrevistado contestó que se trataba de una persona atrapada en el cuerpo de un animal y que sus huesos no aguantaron el calor porque:

$\mathrm{K}$ : - Mo' utz a tokik a winik, tech ma'a tsoy a tokik, a K'isin u tokik a winik! (No está bien que quemes a una persona, ¡Kisin es quien quema a la gente!).

A: - Wä tech a tokik a bäk? (¿Y, si quemas a un animal?).

$\mathrm{K}$ : - K'in tokik u bäkel, u bäke in chik, pero u baker ma'a! U baker a muchik, Mo' utz a tokik! (Yo quemo su cuerpo, su carne es lo que como, ipero no [quemo] sus huesos! Sus huesos se juntan, ¡no es sano quemarlos!).

Este fragmento de entrevista permite retomar la discusión que se ha desarrollado a lo largo del escrito. En primer lugar, se subraya nuevamente que la quema de huesos es atribuida a los seres del inframundo (Kisin, en el caso de los lacandones). De hecho, al poner por error en el fuego al "hombre atrapado en el cuerpo de una presa", sus restos se disuelven. En concepto de los lacandones, lo anterior demostraría que ese animal es en realidad un ser humano metamorfoseado, ya que "las personas no se queman, solo Kisin lo hace”. Además, el entrevistado reitera que está permitido emplear el fuego únicamente para cocer la carne de la presa, mientras que los huesos deben apartarse y conservarse.

\section{Conclusiones}

Tanto entre los antiguos mayas como en las sociedades cazadoras nativas, los restos óseos se consideran como el soporte de determinadas esencias anímicas. Así, estos no pueden ser tratados como elementos inertes o desechos, sino que deben conservarse y queda prohibido quemarlos. En el presente trabajo, se evidenciaron las razones que explican estos cuidados: 1) El "alma" contenida en los huesos es una esencia vital y fértil, necesaria para la conservación de la especie. De hecho, son constantes las asociaciones entre los huesos y algunos elementos que pertenecen al campo semántico de la fertilidad: frutos y plantas, en particular, el maíz. En el caso de los restos humanos, la esencia vital que albergan los vuelve reliquias mágicas y poderosas, también símbolos de continuidad generacional. En el caso de las presas, se considera que algunos intermediarios - los dioses o los dueños de la fauna- pueden regenerar a nuevos animales a partir de los restos de los que fueron sacrificados. 2) A diferencia de las esencias anímicas que se albergan en los órganos vitales, que se separan del organismo después de la muerte, las que se hallan en los huesos son duraderas y se quedan en el plano terrenal. Por lo tanto, pueden convertirse en agentes contaminantes o peligrosos, que toman la forma de "espectros" cuando entran en contacto con los vivos. 3) En el caso específico lacandón, los huesos se conservan también para entregarse a los

EntreDiversidades. Revista de Ciencias Sociales y Humanidades, Vol. 8, Núm. 2 (17), julio-diciembre 2021. Páginas: 30-55 ISSN-e: 2007-7610. https://doi.org/10.31644/ED.V8.N2.2021.A02 
difuntos, para que sean ofrecidos a los perros del Metlan, quienes ayudarán al alma durante su tránsito en el más allá.

Las razones arriba mencionadas explicarían por qué en el área maya y entre algunos pueblos cazadores la cremación no es uno de los métodos primarios para la disposición de los cadáveres. Además, se demostró que en las concepciones mayas sobre el inframundo la práctica de quemar huesos se atribuye generalmente a los seres que moran en el mismo, por lo tanto, es asociada a hábitos no-humanos. Se presentaron datos etnográficos recabados en las comunidades lacandonas para ilustrar las creencias locales sobre el tratamiento de los despojos de las presas; se explicó que estos retienen un principio latente de vitalidad, necesario para la regeneración de las especies cazadas, una lógica que se inserta en las concepciones escatológicas mayas, en donde se concibe a la muerte como una parte esencial del ciclo vital, no como la aniquilación de los seres. De este modo, la conservación de las propiedades vitales contenidas en los huesos es fundamental para que el ciclo no se interrumpa y se permita a la vida brotar nuevamente de la muerte. En el caso de impedir este proceso, el cazador se enfrentará a castigos de varios tipos, llevados a cabo por los dueños de la fauna, o bien por las esencias contendidas en los huesos, que se convertirán en "demonios" y cobrarán su venganza contra el hombre o sus familiares.

\section{Bibliografía citada}

Anderson, Elyse M. (2009). Exploring Maya Ritual Fauna: Caves and the Proposed Link with Contemporary Hunting Ceremonialism. Thesis presented to obtain the degree of Master of Arts. Graduate School of the University of Florida: University of Florida. También disponible en: https://ufdc.ufl.edu/UFE0024821/00001

Anderson, Eugene Newton y Tzuc Medina, Félix (2005). Animals and the Maya in Southeast Mexico. Tucson, Arizona, United States of America: The University of Arizona Press.

Århem, Kaj (1996). "The Cosmic Food Web: Human-Nature Relatedness in the Northwest Amazon”, en Descola, Philippe y Palsson, Gisli (eds.). Nature and Society. London, United Kingdom, New York, United States of America: Routledge, pp. 186-204. También disponible en: https://www.taylorfrancis.com/chapters/edit/10.4324/9780203451069_ 18/cosmic-food-web-human-nature-relatedness-northwest-amazon-kaj\%C3\%A5rhem-philippe-descola-gisli-palsson

Århem, Kaj (2001). "Ecocosmología y chamanismo en el Amazonas: variaciones sobre un tema”. Revista Colombiana de Antropología [en línea], Vol. 37, enero-diciembre, pp. 268-288. Disponible en http://www.redalyc.org/articulo.oa?id=105015287010 (Consultado el 20 de octubre de 2018).

Ávalos, Eugenio Maurer y Guzmán, Avelino (1985). "Una leyenda tzeltal: el infierno o k’atimbak (calentar con huesos)". Tlalocan [en línea], Vol. 10, pp. 257-272. doi: https://doi.org/10.19130/iifl.tlalocan.1985.107 (Consultado el 16 de junio de 2020).

EntreDiversidades. Revista de Ciencias Sociales y Humanidades, Vol. 8, Núm. 2 (17), julio-diciembre 2021. Páginas: 30-55 ISSN-e: 2007-7610. https://doi.org/10.31644/ED.V8.N2.2021.A02 
Baer, Philip y Baer, Mary (1950). Lacandon Ethnographic Material. Microfilm Collection of Manuscripts on Middle American Cultural Anthropology, No. 34. Chicago, United States of America: University of Chicago Library.

Baer, Phillip y Merrifield, William R. (1972). Los Lacandones de México, dos estudios. México: Instituto Nacional Indigenista, Secretaría de Educación Pública.

Bassie-Sweet, Karen y Hopkins, Nicholas (2018). Maya Narrative Arts. Louisville, United States of America: University Press of Colorado. También disponible en: https://www.jstor.org/ stable/j.ctv8pzdkr

Blom, Frans (1954). "Ossuaries, Cremation and Secondary Burials among the Maya of Chiapas, Mexico”. Journal de la Societé des Américanistes [en línea], Núm. 43, pp. 123-135. Disponible en: https://www.persee.fr/doc/jsa 0037-9174_1954 num $43 \quad 1 \quad 2418$ (Consultado el 10 de octubre de 2020).

Boremanse, Didier (1998). Hach Winik: The Lacandon Maya of Chiapas, Southern Mexico. New York, United States of America: Institute of Mesoamerican Studies, The University at Albany.

Boremanse, Didier (2006). Cuentos y mitología de los Lacandones. Contribución al estudio de la tradición oral maya. Guatemala: Academia de Geografía e Historia de Guatemala.

Boremanse, Didier (2020). Ruins, Caves, Gods \& Incense Burners, Northern Lacandon Maya Myths and Rituals. Salt Lake City, United States of America: The University of Utah Press.

Braakhuis, Edwin (2001). "The Way of All Flesh: Sexual Implications of the Mayan Hunt". Anthropos [en línea], 96 (2), pp. 391-409. Disponible en: https://www.academia. edu/7263066/The Way of All Flesh Sexual Implications of the Mayan Hunt (Consultado el 10 de septiembre de 2020).

Brelich, Angelo (2002 [1970]). "Prolegómenos a una historia de las religiones", en Puech, Henri-Charles (dir.). Historia de las religiones antiguas, Volumen I. México, España: Siglo Veintiuno Editores, pp. 30-97.

Brown, Linda A. (2005). "Planting the Bones: Hunting Ceremonialism at Contemporary and Nineteenth Century Shrines in the Guatemalan Highlands". Latin American Antiquity, 16 (2), pp. 131-146. doi: https://doi.org/10.2307/30042808 (Consultado el 20 de octubre de 2020).

Brown, Linda A. (2009). "Communal and Personal Hunting Shrines Around Lake Atitlan, Guatemala”. Maya Archaeology [en línea], Vol. 1, pp. 36-59. Disponible en: https://www. academia.edu/368443/Communal and Personal Hunting Shrines Around Lake Atitlan Guatemala (Consultado el 5 de agosto de 2019).

Brown, Linda A. y Emery, Kitty (2008). "Negotiations with the Animate Forest: Hunting Shrines in the Guatemalan Highlands". Journal of Archaeological Method Theory [en línea], 15 (300), pp. 300-337. doi: https://doi.org/10.1007/s10816-008-9055-7 (Consultado el 25 de mayo de 2020).

Bruce, S., et al., (1971). Los Lacandones 2: Cosmovisión Maya. México, D.F., México: Instituto Nacional de Antropología e Historia.

EntreDiversidades. Revista de Ciencias Sociales y Humanidades, Vol. 8, Núm. 2 (17), julio-diciembre 2021. Páginas: 30-55 ISSN-e: 2007-7610. https://doi.org/10.31644/ED.V8.N2.2021.A02 
Bruce, Roberto (1974). El Libro de Chan K’in (Textos lacandones). México: Instituto Nacional de Antropología e Historia.

Carlsen, Robert S. y Prechtel, Martin (1991). "The Flowering of the Dead: An Interpretation of Highland Maya Culture”. Man [en línea], 26 (1), pp. 23-42. doi: https://doi. org/10.2307/2803473 (Consultado el 6 de septiembre de 2019).

Carmack, Robert (2018). "Anotaciones sobre el Popol Wuj". Popol Wuj: Nueva traducción y comentarios. Ciudad de Guatemala, Guatemala: Publicaciones Mesoamericanas, pp. 271-372.

Cayón, Luis (2012). "Gente que come gente: a propósito del canibalismo, la caza y la guerra en la Amazonía”. Maguaré [en línea], 26 (2), julio-diciembre, pp. 19-49. Disponible en: https://revistas.unal.edu.co/index.php/maguare/article/view/37910 (Consultado el 6 de agosto de 2018).

Ciudad Ruiz, Andrés, Mario Humberto Ruz y María Josefa Ponce de León (coord.) (2005). Antropología de la eternidad: la muerte en la cultura maya. México, D.F., México: Sociedad Española de Estudios Mayas, Universidad Nacional Autónoma de México.

Cook, Suzanne (2019). Xurt'an: The End of the World and Other Myths, Songs, Charms and Chants by the Northern Lacandones of Naha'. Lincoln, United States of America: University of Nebraska Press.

Craveri, Michela Elisa (2012). El lenguaje del mito: voces, formas y estructura del Popol Vuh. Centro de Estudios Mayas, cuaderno 37. México, D.F., México: Universidad Nacional Autónoma de México, Instituto de Investigaciones Filológicas, Centro de Estudios Mayas. También disponible en: https://www.iifilologicas.unam.mx/ebooks/el-lenguaje-del-mito/

Dehouve, Danièle (2008). "El venado, el maíz y el sacrificado. Diario de Campo". Cuadernos de Etnología [en línea], Núm. 4, mayo a junio, pp. 1-39. Disponible en: http://www. danieledehouve.com/images/articles/dehouve-venado.pdf (Consultado el 22 de mayo de 2020).

De la Garza Camino, Mercedes (1978). El hombre en el pensamiento náhuatl y maya. Cuadernos del Centro de Estudios Mayas, 14. México, D.F., México: Instituto de Investigaciones Filológias, Centro de Estudios Mayas, Universidad Nacional Autónoma de México. También disponible en: https:/www.iifl.unam.mx/uploads/popolVuh/artsCaps/ elHombreSuOrigen.pdf

De la Garza Camino, Mercedes (1984). El universo sagrado de la serpiente entre los mayas. México, D.F., México: Universidad Nacional Autónoma de México.

Dillon, Brian (1988). "Meatless Maya? Ethnoarchaeological Implications for Ancient Subsistence". Journal of New World Archaeology, 7 (2/3), pp. 59-70.

Eberl, Markus (2005). Muerte, entierro y ascensión: ritos funerarios entre los antiguos mayas. Mérida, México: Universidad Autónoma de Yucatán.

Fausto, Carlo (2002). "Banquete de gente: comensalidade e canibalismo na Amazônia". Mana [en línea], 8 (2), pp. 7-44. doi: http://dx.doi.org/10.1590/S0104-93132002000200001 (Consultado el 21 de mayo de 2020).

EntreDiversidades. Revista de Ciencias Sociales y Humanidades, Vol. 8, Núm. 2 (17), julio-diciembre 2021. Páginas: 30-55 ISSN-e: 2007-7610. https://doi.org/10.31644/ED.V8.N2.2021.A02 
Fitzsimmons, James L. (2009). Death and the Classic Maya Kings. Austin, Unted States of America: University of Texas Press.

Fitzsimmons, James L. y Fash, William (2005). “Susaj B’aak: muerte y ceremonia mortuoria en la Plaza Mayor de Copán”, en Ciudad Ruiz, Andrés, Mario Humberto Ruz y María Josefa Iglesias Ponce de León (coords.). Antropología de la eternidad: la muerte en la cultura maya. México: Sociedad Española de Estudios Mayas, Universidad Nacional Autónoma de México, pp. 299-316.

Frazer, James George (1944 [1890]). La rama dorada: magia y religión. México, D.F., México, Madrid, España, Buenos Aires, Argentina: Fondo de Cultura Económica.

Gabriel, Marianne (2010). "Ritualidad y cosmovisión: las ceremonias agrarias de los campesinos mayas en Yucatán”, en Fernández Repetto, Francisco (ed.). Estampas Etnográficas de Yucatán. Mérida, México: Ediciones de la Universidad Autónoma de Yucatán, pp. 13-41.

Girard, Rafael (1962). Los Mayas eternos. México, D.F., México: Mex Editores.

Guiteras Holmes, Calixta (1965). Los peligros del alma, Visión del mundo de un tzotzil. México, D.F., México: Fondo de Cultura Económica.

Hamayon, Roberte (2009). Chamanismos de ayer y hoy: seis ensayos de etnografía e historia siberiana, Selección de textos y coordinación de la traducción Roberto Martínez y Natalia Gabayet. México: Universidad Nacional Autónoma de México. También disponible en: https://www.historicas.unam.mx/publicaciones/publicadigital/libros/chamanismos/ historia siberiana.html

Harald, Thomass (2010). “Jeets' lu’um’. Asentar la tierra. Análisis de un rito maya de Yucatán”. Itinerarios [en línea], Vol. 11, pp. 35-54. Disponible en: http://itinerarios.uw.edu.pl/wp_ content/uploads/2014/11/02 Thomass Itin-2010-11.pdf (Consultado el 15 de junio de 2020).

Herrera-Flores, Belén, et al. (2018). "Creencias y prácticas rituales en torno a la cacería de subsistencia en comunidades del norte de Yucatán, México”. Revista Etnobiología [en línea], 16 (1), pp. 5-18. Disponible en: https://dialnet.unirioja.es/servlet/ articulo? codigo=6533099 (Consultado el 14 de mayo de 2020).

Houston, Stephen, David Stuart y Karl Taube (2006). The Memory of the Bones, Body, Being and Experience among the Classic Maya. Austin, United States of America: University of Texas Press.

Jensen, Adolf Ellegard (1986 [1966]). Mito y culto entre pueblos primitivos. México, D.F., México: Fondo de Cultura Económica.

Köhler, Ulrich (2007). "Los dioses de los cerros entre los tzotziles en su contexto interétnico". Estudios de Cultura Maya, Vol. 30, pp. 139-152. También disponible en: http://dx.doi.org/10.19130/iifl.ecm.2007.30.625 
La Chica Delgado, María Cruz (2017). "Sombrerón y la mula: el viaje al otro mundo en un relato maya”, en Carranza Vera, Claudia Verónica, Nora Danira López Torres y Mercedes Zavala Gómez del Campo (eds.). Irás y no volverás. El viaje en formas narrativas de la literatura tradicional de México. San Luis Potosí, México: El Colegio de San Luis, pp. 345-376. También disponible en: https://www.academia.edu/40093731/Sombrer\%C3\%B3n_y la mula El viaje al Otro Mundo en un relato maya

Landa, Diego de (1986 [1959]). Relación de las Cosas de Yucatán. México, D.F., México: Porrúa. Laughlin, Robert Moody (1977). Of Cabbages and Kings, Tales from Zinacantán. Smithsonian Contributions to Anthropology, Number 23. Washington, United States of America: Smithsonian Institution Press.

Lenkersdorf, Carlos (2010). B'omak'umal Tojol'ab'al-Kastiya, Diccionario Tojolabal-Español, Tercera Edición. Disponible en: https://www.rebelion.org/docs/123766.pdf (Consultado el 2 de marzo de 2020).

Lévi-Bruhl, Lucien (1985 [1927]). El alma primitiva. Barcelona, Espańa: Ediciones Península. López Austin, Alfredo (1980). Cuerpo Humano e Ideología. Las concepciones de los antiguos nahuas. México, D.F., México: Instituto de Investigaciones Antropológicas, Universidad Nacional Autónoma de México.

Lot-Falck, Éveline (2018 [1953].) I riti di caccia dei popoli siberiani. Milano, Italia: Adelphi.

Marion Singer, Marie-Odile (1991). Los hombres de la selva: un estudio de tecnología cultural en un medio selvático. México: Instituto Nacional de Antropología e Historia.

Marion Singer, Marie-Odile (1999). El poder de las hijas de Luna. México: Plaza y Valdés.

Martínez González, Joaquín Roberto (2007). "El alma de Mesoamérica, unidad y diversidad en las concepciones anímicas". Journal de la Societé des Américanistes [en línea], 93 (2), pp. 7-41. doi: https://doi.org/10.4000/jsa.7673 (Consultado el 9 de marzo de 2019).

Maza García de Alba, Rocío (2009). "Pisom Qaq’al: la majestad envuelta. Poder, reliquias y el 'poder de las reliquias' entre los mayas prehispánicos”. Estudios de Cultura Maya [en línea], Vol. 53, pp. 173- 204. doi: http://dx.doi.org/10.19130/iifl.ecm.2019.53.948 (Consultado el 27 de mayo de 2020).

Medina Hernández, Andrés (1991). Tenejapa: familia y tradición en un pueblo tzeltal. Tuxtla Gutiérrez, México: Gobierno del Estado de Chiapas, Consejo Estatal de Fomento a la Investigación y Difusión de la Cultura.

Meehan, Pascale (2013). "Putting out the Fire": Tracing Continuity and Change in the Maya Tup k’ak Ceremony”. Mexicon [en línea], 35 (2), pp. 37-42. Disponible en: https://www. jstor.org/stable/43857629?seq=1 (Consultado el 15 de junio de 2020).

Morales Damián, Manuel Alberto (2014). “Mak', rituales agrarios mayas del fuego y del agua en la 'Relación de las cosas de Yucatán”. 'Ilu, Revista de Ciencias de las Religiones [en línea], Vol. 19, pp. 173-191. doi: https://doi.org/10.5209/rev ILUR.2014.v19.46616 (Consultado el 15 de junio de 2020).

Nadasdy, Paul (2007). "The Gift in the Animal: The Ontology of Hunting and HumanAnimal Sociality”. American Ethnologist [en línea], 34 (1), pp. 25-43. doi: https://doi. org/10.1525/ae.2007.34.1.25 (Consultado el 17 de mayo de 2019).

EntreDiversidades. Revista de Ciencias Sociales y Humanidades, Vol. 8, Núm. 2 (17), julio-diciembre 2021. Páginas: 30-55 ISSN-e: 2007-7610. https://doi.org/10.31644/ED.V8.N2.2021.A02 
Nájera Coronado, Martha Ilia (2002). "Rituales y hombres religiosos", en De la Garza Camino, Mercedes y Nájera Coronado, Martha Ilia (eds.). Religión Maya, Enciclopedia Iberoamericana de Religiones. Madrid, España: Editorial Trotta, pp. 115-138.

Nájera Coronado, Martha Ilia (2019). "El lenguaje ritual del fuego en los mayas del Periodo Clásico: Un acercamiento”. Estudios de cultura maya, Vol. 54, pp. 91-127. También disponible en: http://dx.doi.org/10.19130/iifl.ecm.2019.54.993

Neurath, Johannes (2008). "Cacería ritual y sacrificios huicholes: entre depredación y alianza, intercambio e identificación”. Journal de la Société des Américanistes [en línea], 94 (1), pp. 251-283. doi: https://doi.org/10.4000/jsa.9873 (Consultado el 14 de mayo de 2020).

Olivier, Guilhem (2015). Cacería, sacrificio y poder en Mesoamérica. Tras las huellas de Mixcóatl, "Serpiente de Nube". México: Fondo de Cultura Económica, Universidad Nacional Autónoma de México, Instituto de Investigaciones Históricas, Centro de Estudios Mexicanos y Centroamericanos.

Osorio-López, Dulce, et al. (2017). "Cacería y cosmovisión en una comunidad ayuuk en San José el Paraíso, Oaxaca, México”. Revista Etnobiologia [en línea], 15 (3), pp: 54-66. Disponible en: https://dialnet.unirioja.es/servlet/articulo?codigo=6237986 (Consultado el 20 de abril de 2020).

Palka, Joel Wade (2005). Unconquered Lacandon Maya: Ethnohistory and Archaeology of Indigenous Cultural Change. Maya Studies Series. Gainesville, United States of America: University Press of Florida.

Palka, Joel Wade (2014). Maya Pilgrimage to Ritual Landscapes: Insights from Archaeology, History, and Ethnography. Albuquerque, United States of America: University of New Mexico Press.

Palka, Joel Wade (2018). "Where There's Fire, There's Smoke, Lacandon Maya Burning Rites and Cremation Symbolism", en Tiesler, Vera y Scherer, Andrew (eds.). Smoke, Flames, and the Human Body in Mesoamerican Ritual Practice. Washington D.C., United States of America: Dumbarton Oaks Research Library and Collection, pp. 287-320.

Peretti, Leda (2015). "El resurgimiento maya y la resignificación del temazcal como terapéutica ritual”. Scripta Ethnologica [en línea], Vol. 37, pp. 7-16. Disponible en: https://www. redalyc.org/pdf/148/14845594001.pdf (Consultado el 14 de junio de 2020).

Petrich, Perla (2007). "Espacios sagrados entre los mayas del lago Atitlán”. Estudios de Cultura Maya [en línea], Vol. 29, pp. 141-153. Disponible en: https://revistas-filologicas.unam. mx/estudios-cultura-maya/index.php/ecm/article/view/114/114 (Consultado el 16 de junio de 2020).

Pitarch, Pedro Ramón (1996). Ch’ulel: una etnografía de las almas tzeltal. México: Fondo de Cultura Económica.

Pitarch, Pedro Ramón (2013). La cara oculta del pliegue: ensayos de antropología indígena. México: Artes de México, Consejo Nacional para la Cultura y las Artes.

EntreDiversidades. Revista de Ciencias Sociales y Humanidades, Vol. 8, Núm. 2 (17), julio-diciembre 2021. Páginas: 30-55 ISSN-e: 2007-7610. https://doi.org/10.31644/ED.V8.N2.2021.A02 
Plata, Elías, et al. (2019). "Sociocultural Importance of Dogs (Canis lupus familiaris) in Maya Subsistence Hunting: Revelations from Their Participation in the Traditional Group Hunting (Batida) in Yucatan”. Tropical Conservation Science [en línea], Vol. 12, pp. 1-11. doi: https://doi.org/10.1177/1940082919830829 (Consultado el 13 de abril de 2020).

Ramírez Barajas, Pablo Jesús y Naranjo Piñera, Eduardo (2007). "La cacería de subsistencia en una comunidad de la zona maya”. Etnobiología [en línea], 5 (1), pp. 65-85. Disponible en: https://revistaetnobiologia.mx/index.php/etno/article/view/236 (Consultado el 14 de mayo de 2020).

Recinos, Adrián (trad.) (1993). Popol Vuh, Las antiguas historias del Quiché. México: Fondo de Cultura Económica, Colección Popular.

Redfield, Robert y Villa Rojas, Alfonso (1962 [1934]). Chan Kom, a Maya Village. Chicago, United States of América: Phoenix Books, The University of Chicago Press.

Romero Sandoval, Roberto (2017). El Inframundo de los antiguos mayas. México: Centro de Estudios Mayas, Instituto de Investigaciones Filológicas, Universidad Nacional Autónoma de México.

Ruz Lhuillier, Alberto (1991). Costumbres funerarias de los antiguos mayas. México: Fondo de Cultura Económica (Sección Obras de Antropología).

Santos-Fita, Dídac, et al. (2013). "La milpa comedero-trampa como una estrategia de cacería tradicional maya”. Estudios de Cultura Maya, Vol. 42, pp. 87-118. También disponible en: https://revistas-filologicas.unam.mx/estudios-cultura-maya/index.php/ecm/article/ view/126

Santos-Fita, Dídac, et al. (2015). "Symbolism and Ritual Practices Related to Hunting in Maya Communities from Central Quintana Roo, Mexico". Journal of Ethnobiology and Ethnomedicine [en línea], 11 (71) pp. 1-13. doi: https://doi.org/10.1186/s13002-0150055-x (Consultado el 14 de mayo de 2020).

Schele Linda y Freidel, David (2011). Una selva de reyes. La asombrosa historia de los antiguos mayas. México: Fondo de Cultura Económica, Sección Obras de Antropología.

Scherer, Andrew K. (2015). Mortuary Landscapes of the Classic Maya: Rituals of Body and Soul. Austin, United States of America: University of Texas Press.

Sotelo Santos, Laura Elena y Craveri, Michela (2017). Popol Vuh, Serie Xoc-Na Helena Ediciones Especiales. México: Universidad Nacional Autónoma de México.

Soustelle, Georgette (1966). Catalogues du Musée de L’Homme. Serie H, Amérique III, Collections Lacandons. Paris, France: Muséum National D’Historie Naturelle.

Tedlock, Barbara (1992). Time and the Highland Maya. Albuquerque, United States of America: University of New Mexico Press. También disponible en: https://www.academia.edu/4380893/Barbara Tedlock Time and the Highland Maya 1992

Thompson Sidney, John Eric (1930). Ethnology of the Mayas of Southern and Central British Honduras. Chicago, United States of America: Field Museum of Natural History. También disponible en: https://archive.org/details/ethnologyofmayas172thom/page/n3/ mode/2up

EntreDiversidades. Revista de Ciencias Sociales y Humanidades, Vol. 8, Núm. 2 (17), julio-diciembre 2021. Páginas: 30-55 ISSN-e: 2007-7610. https://doi.org/10.31644/ED.V8.N2.2021.A02 
Thompson Sidney, John Eric (1982 [1970]). Historia y Religión de los Mayas. México, D.F., México: Siglo Veintiuno Editores.

Tozzer, Alfred M. (1907). A Comparative Study of the Mayas and the Lacandones. New York, United States of America: Mc. Millan Co. También disponible en: https://archive.org/ details/comparativestudy00tozzrich

Trench, Tim (2005). "Representaciones y sus impactos: el caso de los lacandones en la Selva Lacandona". LiminaR. Estudios Sociales y Humanisticos, 3 (2), julio-diciembre, pp. 4869. San Cristóbal de las Casas, México: Universidad de Ciencias y Artes de Chiapas. doi: https://doi.org/10.29043/liminar.v3i2.182 (Consultado el 15 de septiembre de 2018).

Tuz Chi, Lázaro Hilario (2009). Asi es nuestro pensamiento. Cosmovisión e identidad en los rituales agrícolas de los mayas peninsulares. Tesis para obtener el grado de Doctor en Antropología. Instituto de Iberoamérica, Facultad de Ciencias Sociales, Universidad de Salamanca. Disponible en: https:/gredos.usal.es/handle/10366/76581 (Consultado el 9 de agosto de 2020).

Velásquez García, Érik (2009). Los vasos de la entidad política de 'Ik': una aproximación históricoartística. Estudio sobre las entidades animicas y el lenguaje gestual y corporal en el arte maya clásico. Tesis para obtener el grado de Doctor en Historia del Arte. Facultad de Filosofía y Letras, División de Estudios de Posgrado, Universidad Nacional Autónoma de México. Disponible en: https://ru.dgb.unam.mx/handle/DGB UNAM/TES01000651153 (Consultado el 12 de octubre de 2017).

Villa Rojas, Alfonso (1992). Los Elegidos de Dios, Etnografía de los mayas de Quintana Roo. México, D.F., México: Instituto Nacional Indigenista.

Vogt Zartman, Evon (1979). Ofrendas para los dioses, Análisis simbólico de rituales zinacantecos. México: Fondo de Cultura Económica.

Webster, David (2006). "Studying Maya Burials”, en Whittington, Stephen y Reed, David (eds.). Bones of the Maya, Studies of Ancient Skeletons. Tuscaloosa, Alabama, United States of America: The University of Alabama Press, pp. 3-12.

Willerslev, Rane (2004). "Not Animal, Not Not-Animal: Hunting, Imitation and Empathetic Knowledge among the Siberian Yukaghirs". The Journal of the Royal Anthropological Institute [en línea], 10 (3), pp. 629-652. doi: https://doi.org/10.1111/j.1467-9655.2004.00205.x (Consultado el 15 de septiembre de 2019).

EntreDiversidades. Revista de Ciencias Sociales y Humanidades, Vol. 8, Núm. 2 (17), julio-diciembre 2021. Páginas: 30-55 ISSN-e: 2007-7610. https://doi.org/10.31644/ED.V8.N2.2021.A02 